\title{
ПЕРСПЕКТИВНЫЕ МЕТОДЫ ИЗГОТОВЛЕНИЯ ВЫСОКОЭФФЕКТИВНЫХ ПЬЕЗОЭЛЕКТРИЧЕСКИХ ПРЕОБРАЗОВАТЕЛЕЙ
}

\author{
М. А. Мараховский, А. Е. Панич, В. А. Мараховский \\ МИХАИЛ АЛЕКСЕЕВИЧ МАРАХОВСКИЙ - к.т.н., начальник сектора Научного конструкторско-техно- \\ логического бюро «Пьезоприбор» Южного федерального университета. E-mail: marmisha@mail.ru.
}

АНАТОЛИЙ ЕВГЕНЬЕВИЧ ПАНИЧ - д.т.н., профессор, директор Научного конструкторско-технологического бюро «Пьезоприбор» Южного федерального университета. E-mail: panich@sfedu.ru.

ВЛАДИМИР АЛЕКСЕЕВИЧ МАРАХОВСКИЙ - инженер Научного конструкторско-технологического бюро «Пьезоприбор» Южного федерального университета. E-mail: deтиег@таil.ru.

344090 г. Ростов-на-Дону, ул. Мильчакова, 10, Научное конструкторско-технологическое бюро «Пьезоприбор» Южного федерального университета.

В работе исследована возможность изменения свойств пьезокерамических материалов различных функииональных групп. Цель работы заключалась в вариации свойств пьезокерамики на этапе изготовления, с помощью изменения технологических факторов при постоянной химической композиции. Микроструктура пьезокерамики формируется в процессе ее спекания, при этом формируется и важнейшие механические свойства - плотность, твёрдость, влияющие на электрофизические свойства. Следовательно, корректируя процесс формирования микроструктуры, можно изменять и электрофизические свойства пьезокерамики. Методы горячего прессования и искрового плазменного спекания позволяют эффективно корректировать процесс формирования микроструктуры спекаемой пьезокерамики. Задача исследования состояла в использовании указанных методов при спекании пьезокерамических материалов различных функциональных групп и вариации их параметров. В результате исследования подтверждена эффективность предлагаемых методов в иеелях изменения функциональных параметров пьезокерамики в широком диапазоне.

Ключевые слова: пьезокерамика, горячее прессование, искровое плазменное спекание, микроструктура, электрофизические параметры.

\section{PROMISING METHODS FOR MANUFACTURING HIGH- PERFORMANCE PIEZOELECTRIC CONVERTERS}

\author{
M.A. Marakhovskiy, A. E. Panich, V.A. Marakhovskiy \\ 10, Milchakova st., Rostov-on-Don, 344090, Russia, Scientific Design and Technological Bureau "Piezopribor" \\ Southern Federal University.
}

The paper studies the possibility of changing the properties of piezoceramic materials of various functional groups. The aim of the work was to vary the properties of piezoceramics at the manufacturing stage, by changing the technological factors at a constant chemical composition. The microstructure of piezoceramics is formed 
during its sintering, and the most important mechanical properties are formed-density, hardness, which affect the electrophysical properties. Therefore, by correcting the microstructure formation process, it is possible to change the electrophysical properties of piezoceramics. Methods of hot pressing and spark plasma sintering allow us to effectively correct the process of forming the microstructure of sintered piezoceramics. The aim of the study was to use these methods for sintering piezoceramic materials of various functional groups and variations in their parameters. The study confirmed the effectiveness of the proposed methods for changing the functional parameters of piezoceramics in a wide range.

Key words: piezoelectric ceramics, hot pressing, spark plasma sintering, microstructure, and electrical properties.

\section{Введение}

Пьезоэлектрическая керамика системы цирконат-титаната свинца (ЦТС) послужила основой для большинства пьезокерамических материалов самых различных применений [1-2]. По мере расширения практического применения для достижения требуемых электрофизических свойств химический состав пьезокерамики модифицировался и усложнялся до многокомпонентных систем [2-4]. Помимо пьезокерамических материалов системы ЦТС, широкое применение получили пьезоэлектрические составы на основе $\mathrm{BaTiO}_{3}, \mathrm{PbTiO}_{3}$, $\mathrm{Pb}\left(\mathrm{Mg}_{1 / 3} \mathrm{Nb}_{2 / 3}\right) \mathrm{O}_{3}$ и $(\mathrm{Na}, \mathrm{K}) \mathrm{NbO}_{3}[2,5]$.

Существует также возможность изменения электрофизических параметров пьезокерамики посредством корректировки технологических факторов на этапе изготовления. Механические параметры (микроструктура, плотность, твёрдость и прочность) формируются на этапе спекания пьезокерамики [2]. Таким образом, условия спекания влияют на будущие электрофизические параметры пьезокерамики, поскольку, пьезоэффект - явление электромеханического преобразования. Особый интерес представляют методы консолидированного спекания - горячее прессование (ГП) и искровое плазменное спекание (ИПС), способные существенно корректировать микроструктуру пьезоэлектрической керамики.

\section{Основная часть}

Сегнетокерамика системы титаната бариястронция, работающая в диапазоне сверхвысокочастотных (СВЧ) режимов $0,7-30 \mathrm{GHz}$ в качестве переключающих и управляющих элементов техники, потеснила традиционные полупроводниковые и ферритовые устройства.

Для применения в ускорительной технике сегнетокерамика $\mathrm{Ba}_{0.55} \mathrm{Sr}_{0.45} \mathrm{TiO}_{3}$ (BST) требует существенного сокращения гистерезисных явлений и снижения диэлектрических потерь $(\operatorname{tg} \delta)$. Такая задача может быть решена введением в базовый со- став примесей $(\mathrm{Mg}, \mathrm{Mn}$, титанат-магния и др.) [67], а также спеканием различными способами: традиционным - в камерной печи (ATM), а также методом искрового плазменного спекания (ИПС).

Сегнетокерамика BST с 80 \% добавкой Mg полученная методом ИПС обладала существенно заниженными диэлектрическими потерями ( $\operatorname{tg} \delta)$ на $40 \%$ и диэлектрической проницаемостью $\left(\varepsilon_{33}^{\mathrm{T}} / \varepsilon_{0}\right)$ на $50 \%$ в сравнении с сегнетокерамикой полученной методом АТМ (таблица). Такие изменения положительно влияют на эффективность устройств CBЧ техники [7]. Сегнетокерамика BST полученная методом ГП имела пониженные значения $\operatorname{tg} \delta$ и $\varepsilon_{33}^{\mathrm{T}} / \varepsilon_{0}$, а также повышенную экспериментальную плотность, относительно метода АТМ. Однако по сравнению с методом ИПС, керамика ГП будет не столько эффективна в устройствах СВЧ. Микроструктура керамик BST полученных всеми рассмотренными методами обладала схожим характером (рис. 1, a-1 - a-3), однако в случае ГП размер зёрен был повышенным (рис. a-2).

Помимо традиционных пьезоматериалов системы ЦТС всё чаще применяются сегнетомягкие пьезоматериалы системы (1-x) $\mathrm{Pb}\left(\mathrm{Mg}_{1 / 3} \mathrm{Nb}_{2 / 3}\right) \mathrm{O}_{3}$ $\mathrm{xPbTiO}_{3}$ (PMN-PT), обладающие повышенными электрофизическими свойствами. Пьезокерамика на основе PMN-PT применяется в многослойных конденсаторах с повышенными значениями диэлектрической проницаемости, актюаторах и микроманипуляторах, а также высокочувствительных преобразователях. Однако при изготовлении пьезоматериалов этой системы возникают проблемы (появление кристаллической структуры пирохлора при синтезе материала и др.). Для минимизации обозначенных проблем, а также совершенствования механических и электрофизических характеристик, было проведено спекание пьезоматериала PMN-PT методами ГП и ИПС (таблица).

Пьезокерамические элементы PMN-PT, спеченные методом ИПС, обладали повышенными на $9 \%$ значениями электрофизических параметров по сравнению с образцами АТМ. Повышенные параметры можно объяснить формированием 
Основные характеристики пьезокерамических элементов

\begin{tabular}{|c|c|c|c|c|}
\hline $\begin{array}{c}\text { Пьезокерамический } \\
\text { материал }\end{array}$ & $\begin{array}{c}\text { Температура } \\
\text { и метод спекания }\end{array}$ & 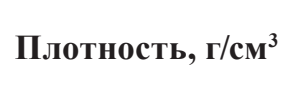 & $\operatorname{tg} \sigma, \%$ & $\varepsilon_{33}^{\mathrm{T}} / \varepsilon_{0}$ \\
\hline \multirow{3}{*}{ BST } & $1300^{\circ} \mathrm{C}$ ATM & 4,13 & 13,57 & 171 \\
\hline & $1200^{\circ} \mathrm{C}$ ГП & 4,24 & 3,15 & 123 \\
\hline & $1100^{\circ} \mathrm{C}$ ИПС & 4,40 & 0,45 & 75 \\
\hline \multirow{3}{*}{ PMN-PT } & $1250^{\circ} \mathrm{C}$ ATM & 7,50 & 0,5 & 1643 \\
\hline & $1180^{\circ} \mathrm{C}$ ГП & 7,77 & 0,7 & 1778 \\
\hline & $1150^{\circ} \mathrm{C}$ ИПС & 7,92 & 0,4 & 1789 \\
\hline \multirow{3}{*}{ Сегнетожёсткий состав } & $1170^{\circ} \mathrm{C}$ ATM & 7,80 & 0,50 & 1307 \\
\hline & $1150^{\circ} \mathrm{C}$ ГП & 7,72 & 0,70 & 1349 \\
\hline & $970{ }^{\circ} \mathrm{C}$ ИПС & 7,98 & 0,49 & 1415 \\
\hline \multirow{3}{*}{ Сегнетомягкий состав } & $980^{\circ} \mathrm{C}$ ATM & 7,81 & 1,98 & 2871 \\
\hline & $980^{\circ} \mathrm{C}$ ГП & 7,86 & 2,18 & 2908 \\
\hline & $980^{\circ} \mathrm{C}$ ИПС & 8,13 & 2,2 & 2919 \\
\hline
\end{tabular}

бездефектной монодисперсной структуры керамики, при спекании методом ИПС (рис. b-3). Спекание пьезокерамики PMN-PT методом ГП также обеспечивает повышение значений пьезоэлектрического модуля $\mathrm{d}_{33}$ на 8 \% по сравнению с АТМ спеканием [8], при схожем характере микроструктур (рис. b-1 - b-2).

Для изготовления пьезопреобразователей, paботающих в режиме излучения, пьезотрансформаторов и устройств силового ультразвука используются сегнетожёсткие пьезокерамические материалы [9]. В качестве объекта исследования использовался многокомпонентный сегнетожёсткий состав $\mathrm{PbZrO}_{3}-\mathrm{PbTiO}_{3}-\mathrm{Pb}\left(\mathrm{Mn}_{1 / 3} \mathrm{Nb}_{2 / 3}\right) \mathrm{O}_{3}-\mathrm{Pb}\left(\mathrm{Zn}_{1 / 3} \mathrm{Nb}_{2 / 3}\right) \mathrm{O}_{3}$.

Сегнетожёсткие пьезокерамические элементы спеченные методами ГП и ИПС имели повышенные значения относительной диэлектрической проницаемости $\varepsilon_{33}^{\mathrm{T}} / \varepsilon_{0}$ на 8 и $16 \%$, соответственно, по сравнению со значениями элементов полученных методом АTM [10]. Оптимальная температура спекания сегнетожёсткой пьезокерамики методом ИПС оказалась на $200{ }^{\circ} \mathrm{C}$ ниже, чем при методе АТМ (таблица). Микроструктура пьезокерамики полученной методом ИПС отличалась плотной упаковкой зерен и отсутствием пор (рис. с-3). В микроструктуре пьезокерамики полученной методом ГП содержалось значительное количество стеклофазы в сочетании с беспористой упаковкой зерен, в сравнении с керамикой ATM (рис. с-2 и с-1, соответственно).
Большой практический интерес представляют многокомпонентные пьезокерамические системы, с повышенными электрофизическими характеристиками, используемые при изготовлении многослойных актюаторов с низковольтным управляющим напряжением. При изготовлении таких актюаторов необходимо согласование температур спекания керамических слоёв с температурой вжигания межслойных токопроводящих электродов. В качестве модельного объекта был выбран многокомпонентный сегнетомягкий пьезоматериал $\mathrm{PbTiO}_{3}-\mathrm{PbZrO}_{3}-\mathrm{Pb}\left(\mathrm{Ni}_{1 / 2} \mathrm{~W}_{1 / 2}\right) \mathrm{O}_{3}-\mathrm{Pb}\left(\mathrm{Cd}_{1 / 2} \mathrm{~W}_{1 / 2}\right) \mathrm{O}_{3}-$ $\mathrm{Pb}\left(\mathrm{Bi}_{2 / 3} \mathrm{~W}_{1 / 3}\right) \mathrm{O}_{3}-\mathrm{Pb}\left(\mathrm{Ni}_{1 / 3} \mathrm{Nb}_{2 / 3}\right) \mathrm{O}_{3}-\mathrm{Pb}\left(\mathrm{Zn}_{1 / 3} \mathrm{Nb}_{2 / 3}\right) \mathrm{O}_{3}$, с температурой спекания ниже $1000{ }^{\circ} \mathrm{C}$. Микроструктура многокомпонентной пьезокерамики полученной методами АТМ, ГП и ИПС подтверждает возможность управления процессом формирования мелкозернистой структуры керамики (рис. d-1 - d-3). Плотная керамическая структура формируется уже при $850{ }^{\circ} \mathrm{C}$.

В результате исследования установлено, что предпочтительным методом спекания пьезокерамики является ИПС. При таком способе температура спекания керамических образцов может быть снижена до $900{ }^{\circ} \mathrm{C}$, с сохранением основных характеристик пьезоэлектрической керамики в сравнении с методом АТМ [11]. Однако максимальные свойства пьезокерамики полученной методом ИПС достигаются при $980{ }^{\circ} \mathrm{C}$ (таблица). 


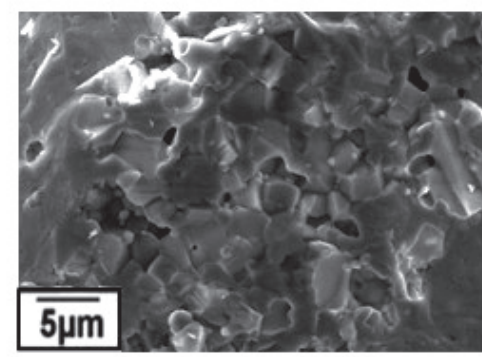

a-1

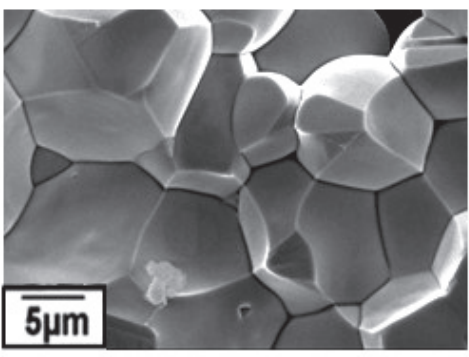

b-1

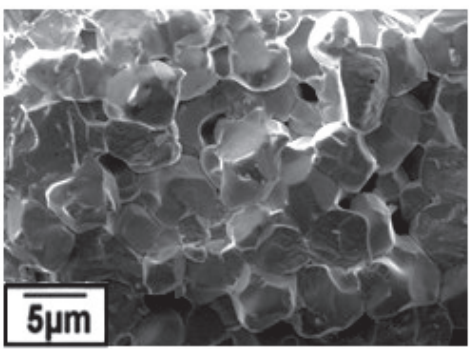

c-1

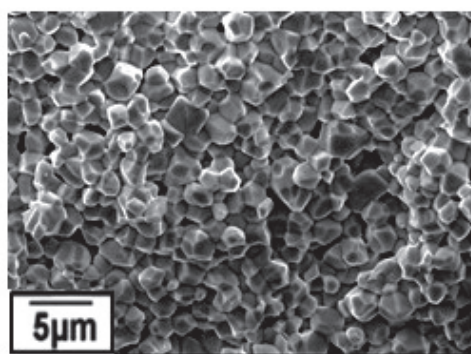

d-1

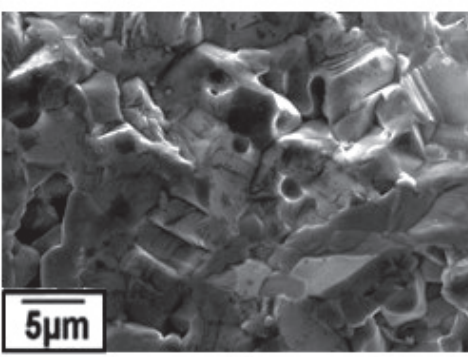

a-2

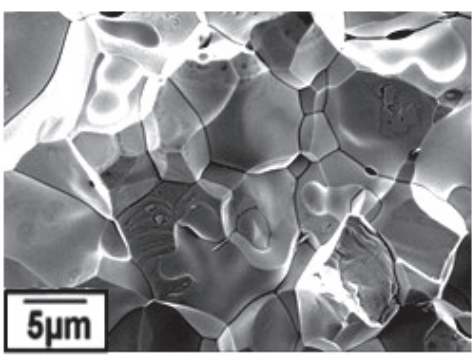

b-2

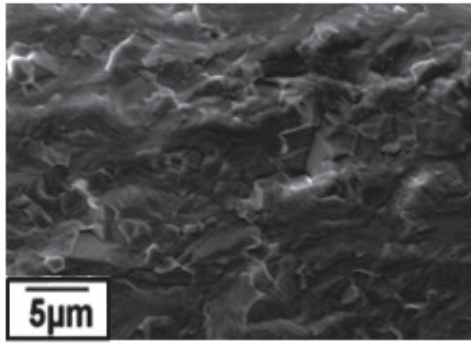

c-2

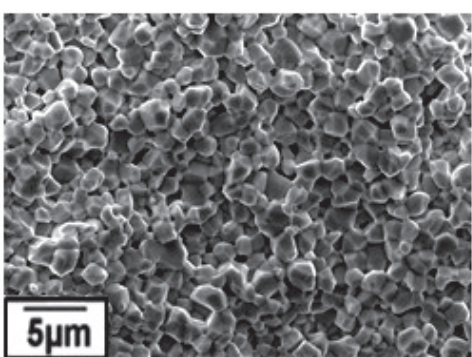

d-2

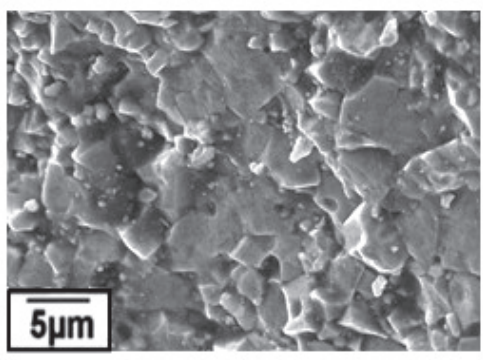

a-3

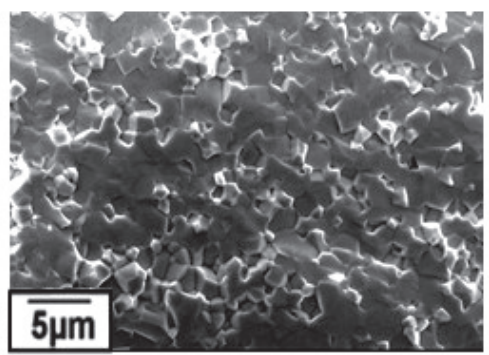

b-2

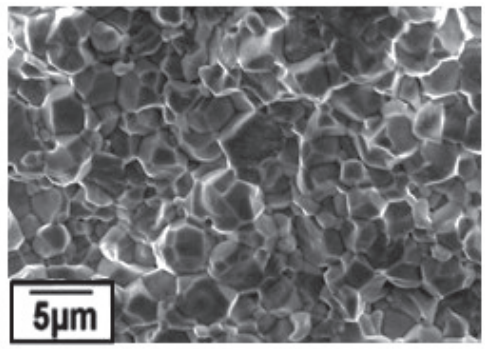

c-3

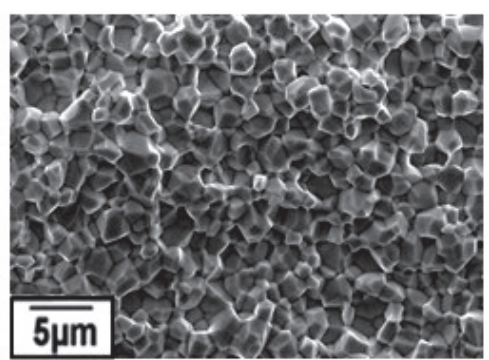

d-3

Рис. Микроструктура пьезокерамических элементов

BST: $\boldsymbol{a}-\mathbf{1}-A T M ; \boldsymbol{a}-\mathbf{2}-Г П ; \boldsymbol{a}-\mathbf{3}-И П С . ~ Р M N-P T: \boldsymbol{b}-\mathbf{1}-A T M ; \boldsymbol{b}-\mathbf{2}-Г П ; \boldsymbol{b}-\mathbf{3}-И П C$

Сегнетожесткий материал: $\boldsymbol{c - 1}$ - АТМ; $\boldsymbol{c}-\mathbf{2}-$ ГП; $\boldsymbol{c}-3-$ ИПС

Сегнетомягкий материал: $\mathbf{d - 1}-$ - АТМ; $\boldsymbol{d}-\mathbf{2}-$ ГП; $\boldsymbol{d - 3}-$ ИПС

\section{Выводы}

Спекание пьезоэлектрической керамики методами ГП и ИПС приводит к формированию плотной бездефектной микроструктуры, обеспечивающей повышение основных электрофизических и механических характеристик. Кроме того, методы ГП и ИПС позволяют проводить процессы спекания керамик при пониженных температурах.
Отдельного внимания заслуживает метод ИПС, обладающий большим потенциалом в возможности целенаправленного формирования требуемой микроструктуры, а, следовательно, и свойств пьезокерамики. Также, метод ИПС способствует не только понижению температур спекания на $150-300{ }^{\circ} \mathrm{C}$, но и сокращающает продолжительность изотермической выдержки (в 36 раз!). Это не только положительно отражается на энергосбережении, но и повышает эффективность 
пьезоэлектрических керамик различных функциональных групп.

\section{Лumepamypa}

1. Куприянов М.Ф., Константинов Г.М., Панич А.Е. Сегнетоэлектрические морфотропные переходы. Ростов-на-Дону: Изд-во Ростов. ун-та, 1991.

2. Фесенко Е.Г., Даничигер А.Я., Разумовская О.Н. Новые пьезокерамические материалы. - Ростов-наДону: Изд-во Ростов. ун-та, 1983.

3. Тополов В.Ю., Панич А.Е. Электронный научный журнал «Исследовано в России». 2008. Рег. N 002. С. 8-26.

4. Панич А.А., Мараховский М.А., Мотин Д.В. Инженерный вестник Дона. 2011. №1. - Режим доступа: http://www.ivdon.ru/magazine/archive/ n1y2011/325 (доступ свободный).

5. Keramik/Hrsq. H. Schaumburq.-Stuttqart: B.G. Tenbner, 1994.

6. Вендик О.Г., Дедык А.И., Дмитриева Р.В., Зайончковский А.Я., Лихолетов Ю.В., Рубан А.С. ФТТ. 1984. Т. 26. Вып. 3. С. 684-689.
7. Мараховский М.А., Панич А.А., Мараховский В.А. Исследование характеристик сегнетокерамики титаната бария-стронция, полученной методом искрового плазменного спекания. INTERMATIC-2018 // Москва. Ч.2. 2018. - 430 с.

8. Мараховский М.А., Панич А.А. Получение пьезокерамики системы PMN-PT методом искрового спекания. Известия ЮФУ. Технические науки. 2017. №6(191). С. 242-249.

9. Шарапов В.М., Минаев В.Г., Сотула Ж.В., Куницкая Л.Г. Электроакустические преобразователи. - Москва: Техносфера, 2013. - 296 с.

10. Мараховский М.А., Панич, А.Е., Мараховский В.А. Влияние технологии спекания на свойства сегнетожёсткой керамики системы ЦТС. Технологии и материалы для экстремальных условий // Агой. 2019. -343 c.

11. Мараховский М.А., Мараховский В.А., Мирющуенко Э.А., Панич Е.А. Исследование возможности создания новых полифазных пьезоматериалов для гидроакустических преобразователей. ГА-2018 // СанктПетербург. 2018. - 616 с. 